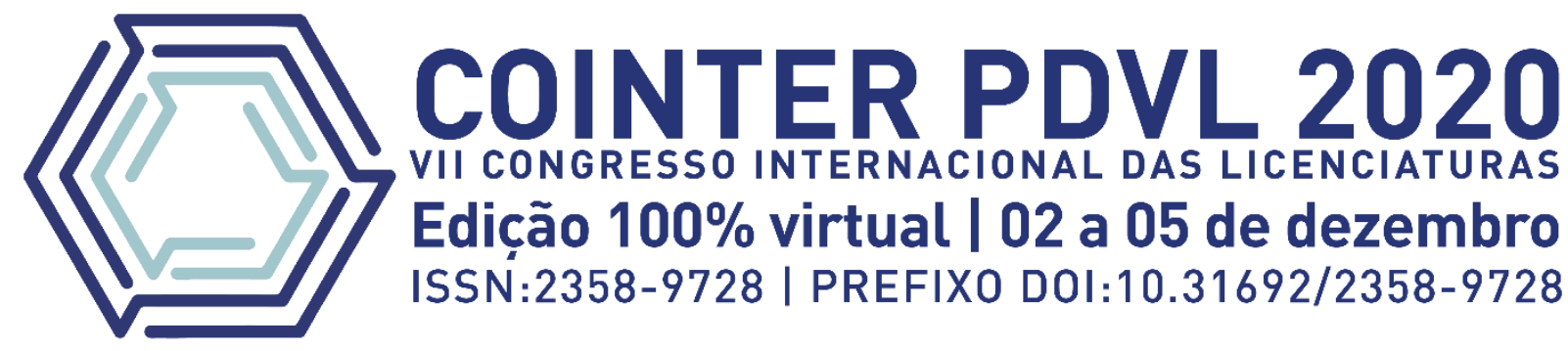

\title{
IMPLEMENTAÇÃO DE ESTRATÉGIAS PARA O ENSINO DOS MÓDULOS III E IV DAS SUJEITAS CIÊNCIAS PARA A CIDADANIA USANDO TIC
}

\author{
IMPLEMENTACIÓN DE ESTRATEGIAS PARA LA ENSEÑANZA DE LOS \\ MÓDULOS III Y IV DE LA ASIGNATURA CIENCIAS PARA LA CIUDADANÍA \\ UTILIZANDO LAS TIC'S
}

\section{IMPLEMENTATION OF STRATEGIES FOR THE TEACHING OF MODULES III AND IV OF THE SUBJECT SCIENCES FOR CITIZENSHIP USING ICT}

\author{
Apresentação: Comunicação Oral \\ Felipe López Sepúlveda ${ }^{1}$, Lastenia Ugalde Meza²
}

DOI: https://doi.org/10.31692/2358-9728.VIICOINTERPDVL.0027

\begin{abstract}
RESUMO
A seguinte pesquisa teve como objetivo desenvolver uma Unidade Didática de Aprendizagem através da Plataforma Exelearning, na qual várias metodologias de ensino e aprendizagem diferentes das indicadas pelo MINEDUC (Ministério da Educação do Chile) foram propostas para a implementação curricular do nova disciplina "Ciências para a Cidadania", especificamente do Módulo III e IV do ensino secundário (secundário), que se torna obrigatória a partir do ano 2020. As metodologias utilizadas na unidade didáctica são: aprendizagem baseada em problemas (PBL) e aprendizagem colaborativo (AC), entre outros. A pesquisa baseia-se na pesquisa-ação como metodologia de trabalho. Participam da pesquisa 22 professores da rede de ensino, os quais devem ministrar os módulos III e IV da referida disciplina. Após a aplicação de um diagnóstico inicial, foram detectados problemas correspondentes a aspectos curriculares e práticos de implementação destes módulos. Com base nos resultados obtidos na primeira fase desta pesquisa, propõe-se a resolução dos nós críticos detectados, desenvolvendo uma Unidade Didática de Aprendizagem que abrangerá conteúdos, atividades e avaliações utilizando diversos recursos multimídia. Feito isso, a Unidade de Aprendizagem Didática foi submetida a uma avaliação por meio do julgamento de especialistas, a fim de verificar se ela permitia a realização de processos de ensino e aprendizagem pertinentes aos Módulos III e IV acima mencionados. Por fim, à luz dos resultados obtidos, concluiu-se que a Unidade de Aprendizagem Didática desenvolvida cumpre de forma eficiente os requisitos fundamentais para a realização da aprendizagem dos módulos III e IV da disciplina de Ciências para a Cidadania.
\end{abstract}

Palavras-chave: Ciências para a cidadania, Metodologias de ensino, Programas de estudos do $3^{\circ}$ e $4^{\circ}$ anos, TICs

\section{RESUMEN}

La siguiente investigación tuvo como objetivo desarrollar una Unidad Didáctica de Aprendizaje a través de la Plataforma Exelearning, en la cual se propusieron diversas metodologías de enseñanza y aprendizaje distintas a las señaladas por el MINEDUC (Ministerio de Educación de Chile) para la implementación curricular de la nueva asignatura "Ciencias para la Ciudadanía", específicamente de

\footnotetext{
${ }^{1}$ Estudiante de Pregrado, Universidad de Playa Ancha,f_lopezsepulveda@upla.cl

${ }^{2}$ Doctora, Universidad de Playa Ancha,lastenia.ugalde@upla.cl
} 
los Módulo III y IV de enseñanza media (secundaria), que es obligatoria a partir del año 2020. Las metodologías utilizadas en la unidad didáctica son: aprendizaje basado en problemas (ABP) y aprendizaje colaborativo (AC), entre otras. La investigación se basa en la investigación-acción como metodología de trabajo. Participan de esta investigación 22 docentes del sistema escolar, los cuales deben impartir los modulos III y IV de la asignatura anteriomente mencionada. Tras la aplicación de un diagnóstico inicial, fueron detectadas problemáticas correspondientes a aspectos curriculares y prácticos para la implementación de dichos módulos. En base a los resultados obtenidos en la primera fase de esta investigación, se propone dar solución a los nudos críticos detectados, elaborando una Unidad Didáctica de Aprendizaje la cual logrará abarcar contenidos, actividades, y evaluaciones utilizando diversos recursos de multimedia. Una vez realizado esto, la Unidad Didáctica de aprendizaje se sometió a valoración a través del juicio de expertos con el fin de verificar que ésta permitiera llevar a cabo procesos de enseñanza y aprendizajes pertinentes a los Módulos III y IV anteriormente mencionados. Finalmente, a la luz de los resultados obtenidos, se logró concluir que la Unidad Didáctica de Aprendizaje desarrollada cumple eficientemente los requerimientos fundamentales para el logro del aprendizaje de los modulos III y IV de la asignatura de Ciencias para la Ciudadanía.

Palabras Clave: Ciencias para la ciudadanía, Metodologías de enseñanza, Programas de estudio $3^{\circ}$ y $4^{\circ}$ medio, TIC's.

\begin{abstract}
The following research aimed to develop a Didactic Learning Unit through the Exelearning Platform, in which various teaching and learning methodologies other than those indicated by the MINEDUC (Ministry of Education of Chile) were proposed for the curricular implementation of the new subject "Sciences for Citizenship", specifically of the Module III and IV of secondary education (secondary), which is compulsory as of the year 2020. The methodologies used in the didactic unit are: problembased learning (PBL) and learning collaborative (AC), among others. The research is based on action research as a work methodology. 22 teachers of the school system participate in this research, who must teach modules III and IV of the aforementioned subject. After applying an initial diagnosis, problems corresponding to curricular and practical aspects for the implementation of these modules were detected. Based on the results obtained in the first phase of this research, it is proposed to solve the critical nodes detected, developing a Didactic Learning Unit which will cover content, activities, and evaluations using various multimedia resources. Once this was done, the Didactic Learning Unit was subjected to an assessment through the judgment of experts in order to verify that it allowed to carry out teaching and learning processes relevant to Modules III and IV mentioned above. Finally, in light of the results obtained, it was concluded that the Didactic Learning Unit developed efficiently meets the fundamental requirements for the achievement of learning of modules III and IV of the subject of Sciences for Citizenship.
\end{abstract}

Keywords: Sciences for citizenship, Teaching methodologies, 3rd and 4th year study programs, ICTs

\title{
INTRODUCCIÓN
}

No es nada nuevo decir que la sociedad tanto Chilena como mundial está en constante cambio. Día a día tanto el mundo como las personas que componen cada sociedad se van transformando, teniendo nuevas demandas y necesidades por las cuales seguir trabajando para avanzar en el desarrollo de la humanidad. Por ende, todo aquello que está inmerso en nuestra sociedad, también cambia y la educación no es una excepción.

La tecnología, de forma general, comprende métodos y procedimientos de los que se ha servido la humanidad para satisfacer sus necesidades y resolver problemas mediante la actividad técnica, aplicando los conocimientos disponibles en cada momento, ya sean 
empíricos o científicos, y la experiencia práctica acumulada en la ejecución de tareas, para inventar, construir o modificar las cosas que componen su entorno material y mejorar así sus condiciones de vida.

Aquí es donde nos encontramos con la tecnología como una herramienta disponible en nuestra actualidad para desarrollar nuevas metodologías de enseñanza tanto para ser aplicadas de forma presencial en aula o en forma digital a distancia.

A partir de este año, comenzó a regir en Chile un nuevo cambio curricular, en el cual introducía la asignatura de Ciencias para la Ciudadanía en reemplazo de las asignaturas de Biología, Química y Física para los niveles de $3^{\circ}$ y $4^{\circ}$ Medio. Esta nueva asignatura, impartida por docentes del área de la Biología, Química y Física, comprende un nuevo desafío para los docentes que durante años se encargaron de impartir su especialidad, es por ello que se realizó esta investigación, la cual pudiera detectar las diversas dificultades y problemáticas docentes acerca de la implementación de esta nueva asignatura para así proponer una estrategia que permitiera dar solución a ellos.

Los nudos críticos detectados durante esta investigación fueron: Problemas de Contenido, Metodologías, Evaluaciones y Capacitación a nivel Nacional para la implementación de la Asignatura de Ciencias para la Ciudadanía.

Es por ello que el Objetivo General de la presente investigación corresponde a generar nuevas estrategias de enseñanza y aprendizaje para la impartición de la asignatura de Ciencias para la Ciudadanía, utilizando las TIC's como herramienta de aprendizaje, solucionando los problemas de aspecto curricular referentes al contenido, metodologías y evaluaciones.

Para ello, Objetivos Específicos que se abordaron durante esta investigación corresponden a:

1. Identificar Software de apoyo para la impartición de los Módulos.

2. Generar diversos recursos didácticos informatizados (RDI) en relación con los Software de apoyo.

3. Complementar metodologías de enseñanza con nuevas alternativas no declaradas por los docentes, tales como: ABP, AC.

4. Generar evaluaciones de los contenidos utilizando las TIC's

5. Desarrollar una plataforma Exelearning para llevar a cabo el proceso de enseñanza y aprendizaje de los Módulos III y IV de la asignatura de Ciencias para la Ciudadanía.

Esta investigación, la cual se trabaja bajo la metodología de investigación acción, permite contribuir a la mejora de la práctica educativa realizada por diferentes profesionales 
de la educación, solucionando problemáticas recientes y actuales sobre la implementación de la asignatura de Ciencias para la Ciudadanía, debido a que el recurso elaborado (Unidad Didáctica de Aprendizaje), permite implementar diversas metodologías y estrategias de enseñanza para realizar evaluaciones y actividades de aprendizaje apoyadas en el uso de diversos recursos didácticos informatizados tales como Software, vídeos, imágenes, entre otros, lo cual fue validado y respaldado por docentes expertos en educación.

\section{FUNDAMENTACIÓN TEÓRICA}

La presente investigación se realizó bajo el modelo de Investigación-Acción, la cual para Eliot (1993), se define como "un estudio de una situación social con el fin de mejorar la calidad de la acción dentro de la misma". Dicho autor, la entiende como una reflexión sobre las acciones humanas y las situaciones sociales vividas por el profesorado que tiene como objetivo ampliar la comprensión de los docentes de sus problemas prácticos. Las acciones van encaminadas a modificar la situación una vez que se logre una comprensión más profunda de los problemas.

Es fundamental recordar las etapas de la Investigación-Acción planteadas por Kemmis (1989), quién menciona que el proceso está integrado por cuatro fases o momentos interrelacionadas: planificación, acción, observación y reflexión, tal como se muestra en la Figura 01.

Figura 01: Momentos de la Investigación-Acción (Kemmis).

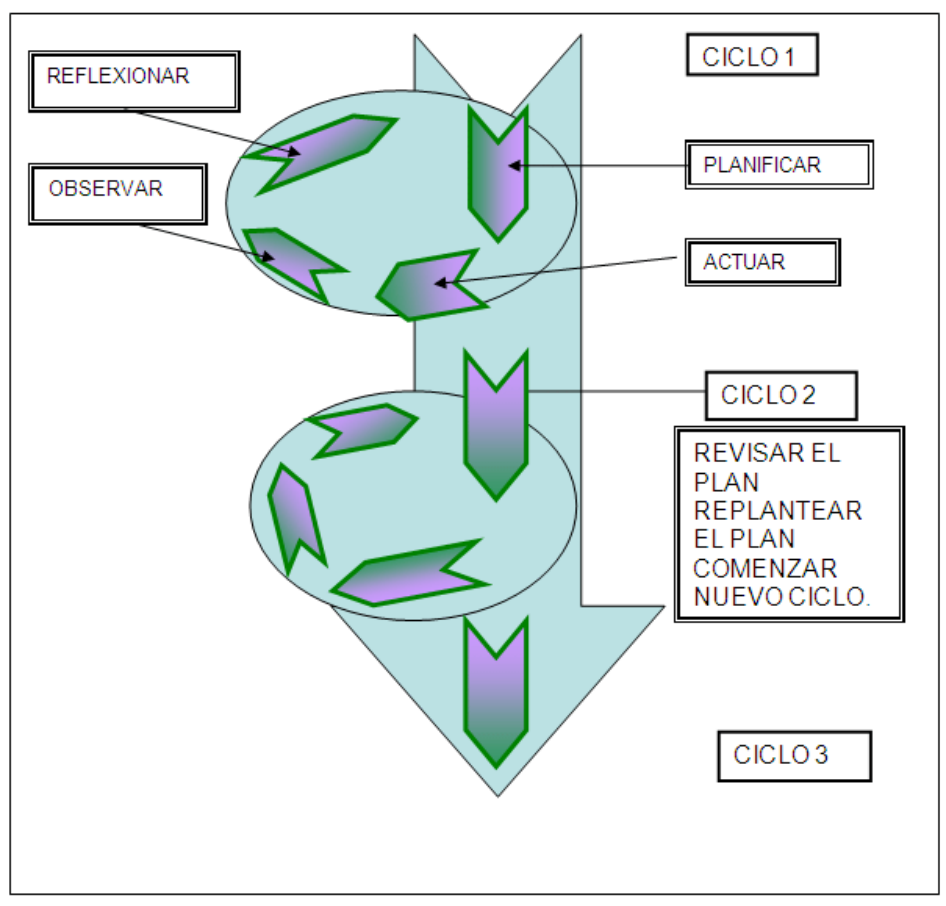

Fuente: Investigación-Acción Conocer y cambiar la práctica educativa, Antonio Latorre. 
Este ciclo de Investigación-Acción fue utilizado para analizar y resolver diversas problemáticas que surgen de la implementación de la nueva asignatura "Ciencias para la Ciudadanía”. Este modelo, que consta de etapas de observación, reflexión, planificación y actuación, permite crear un ciclo de mejora de la práctica educativa, es por ello que esta investigación tiene como objetivo aportar con nuevas herramientas TIC's que permitan desarrollar procesos educativos de la asignatura de Ciencias para la Ciudadanía respondiendo así a las problemáticas docentes detectada en el diagnóstico inicial de esta investigación.

El modelo de Kemmis se representa en una espiral de ciclos, cada ciclo lo componen cuatro momentos:

1) El desarrollo de un plan de acción críticamente informado para mejorar aquello que ya está ocurriendo.

2) Un acuerdo para poner el plan en práctica.

3) La observación de los efectos de la acción en el contexto en el que tienen lugar.

4) La reflexión en torno a esos efectos como base para una nueva planificación, una acción críticamente informada la cual se llevá a cabo a través de ciclos sucesivos.

En el presente trabajo, se desarrolla un plan de acción en función de los nudos críticos detectados tras la aplicación del diagnóstico inicial a una muestra de 22 docentes encargados de impartir la asignatura de Ciencias para la Ciudadanía, el cual permitió conocer cómo se desarrolla y qué dificultades presenta la implementación de esta asignatura. Una vez desarrollado el plan de acción, el cual consistió en la elaboración de una Unidad Didáctica, Exelearning, se realizaron los procesos de observación y reflexión de la Unidad Didáctica en colaboración con los docentes participantes de esta investigación, quienes se encargaron de evaluar y realizar sugerencias para el perfecionamiento de este recurso, generando así una "nueva planificación" en función de la reflexión realizada durante el proceso anterior, con objetivo de reajustar y mejorar la calidad de la Unidad Didáctica desarrollada, permitiendo llevar a cabo nuevamente el Ciclo de la Investigación-Acción.

Parte del interés de exponer este trabajo es exhibir nuevas alternativas de metodologías que representan el uso de las TIC's mediante la plataforma Exelearning. Sin embargo, es importante mencionar que para la realización de investigaciones en educación es fundamental contar con instrumentos confiables, pero también validados.

Para validar la Unidad Didáctica a través del Juicio de Expertos, es fundamental la participación como jueces expertos, donde Robles y Rojas (2015) hacen referencia a la relevancia de fungir como tal; indicando que esta labor es fundamental para "eliminar 
aspectos irrelevantes, incorporar los que son imprescindibles y/o modificar aquellos que lo requieran". En el proceso de validez de contenido se ponen en juego una serie de opiniones argumentadas por parte de los expertos y, aunque no se encuentren acuerdos unánimes, se pueden identificar las debilidades y fortalezas del instrumento. Ello permitirá un análisis profundo por parte del investigador que dará lugar a la toma de decisiones respecto a qué modificar, integrar o eliminar. Esta tarea tiene varias implicaciones para quienes fungen como jueces, porque, además de requerir determinados conocimientos y experiencia, demandan tiempo y organización en sus actividades para poder desarrollarla con oportunidad.

Es por ello, que un grupo de expertos se encargó de analizar y validar la Unidad Didáctica elaborada, corroborando que las diversas metodologías desarrolladas utilizando las TIC's permitieran cumplir con los requerimientos mínimos para llevar a cabo la enseñanza del Módulo III de Ambiente y Sostenibilidad y del Módulo IV de Tecnología y Sociedad.

\section{METODOLOGIA}

La presente investigación, de naturaleza cualitativa-descriptiva, comenzó con la realización de un diagnóstico inicial a una muestra de 22 docentes de área de las Ciencias, quienes desarrollaban su labor tanto en colegios municipales, particulares y particularessubvencionados. La aplicación del diagnóstico tenía como objetivo conocer las problemáticas que aquejan al profesorado respecto a la impartición de las asignaturas de Ciencias para la Ciudadanía.

Una vez realizado el diagnóstico se recolectó y analizó la información obtenida con objetivo de generar redes semánticas que permitieran el análisis global de los problemas docentes acerca de la impartición de la asignatura de Ciencias para la Ciudadanía. Una vez divisado los problemas, se generó el plan de acción, el cual corresponde a la elaboración de una Unidad didáctica que respondiera a las problemáticas docentes, para así cerrar el ciclo de investigación-acción con la validación de la Unidad de Didáctica mediante el juicio de expertos.

Lo anteriormente descrito, corresponde a la adecuación del ciclo de investigaciónacción para esta investigación, tal como lo muestra la Figura 02: 
Figura 02: Adaptación Ciclo de Investigación-Acción.

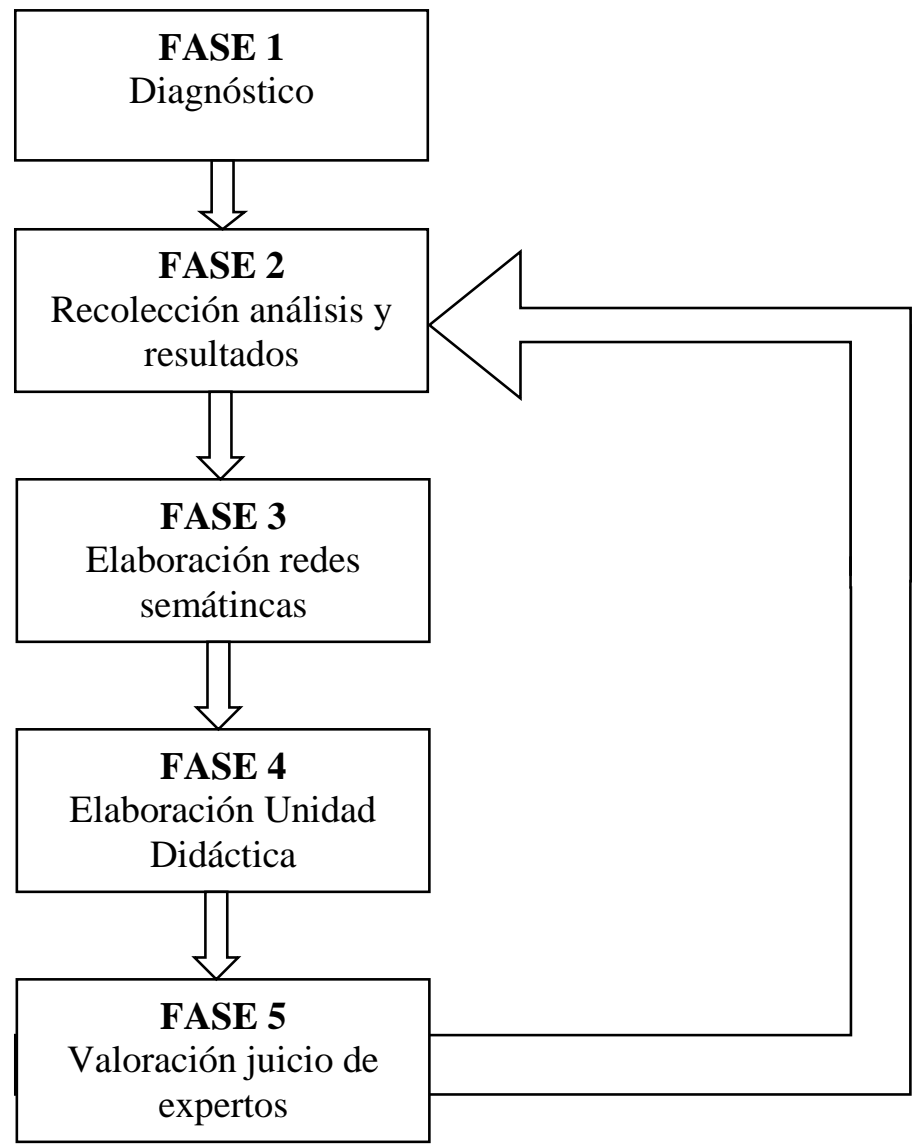

Fuente: Propia (2020).

Este ciclo de investigación-acción, es realizado con objetivo de mejorar e ir readecuando la Unidad Didáctica desarrollada, a través de los resultados obtenidos en el cuestionario de validación de la Fase 5, permitiendo reajustar la Unidad Didáctica según las recomendaciones de los expertos en educación.

La validación de dicha unidad didáctica realizada a través del Juicio de Experto utilizó como instrumento el cuestionario de tesis magistral de la autora Br. Trinidad Milagros Guillermo Parraguez, la cual que tiene como nombre: "Módulo didáctico MATETIC, en Exelearning, en el desarrollo de la capacidad resolución de problemas con ecuaciones en z, en los estudiantes de primer grado de la institución educativa “Amalia Campos de Beleván” del distrito de Pítipo, 2015.”, valorando dimensiones de coherencia, relevancia, claridad y suficiencia fundamentales de la Unidad Didáctica para lograr llevar a cabo procesos de enseñanza y aprendizaje eficientes.

\section{RESULTADOS y DISCUSIÓN}

Unidad Didáctica de Aprendizaje: La unidad didáctica desarrollada presenta una 
IMPLEMENTAÇÃO DE ESTRATÉGIAS PARA O ENSINO DOS MÓDULOS III E IV DAS SUJEITAS CIÊNCIAS PARA A CIDADANIA USANDO TIC

serie de metodologías y estrategias de enseñanza y aprendizaje para llevar a cabo procesos de enseñanza correspondientes a los Módulos III y IV de la asignatura de Ciencias para la Ciudadanía.

A continuación, en la Figura 03, se muestra la portada correspondientes a la Unidad Didáctica elaborada durante esta investigación:

Figura 03: Portada Unidad Didáctica de Aprendizaje.

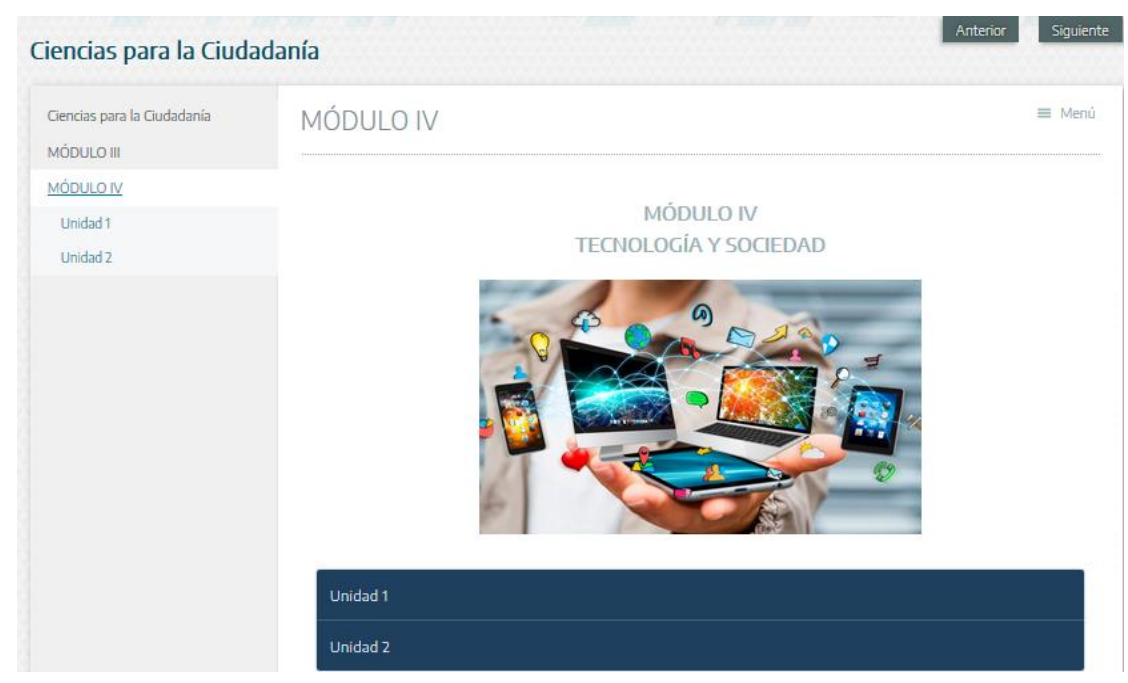

Fuente: Propia (2020).

La estructura de esta unidad didáctica se compone de la siguiente forma:

I) Presentación Módulo y Unidad de aprendizaje a desarrollar: En la cual se presentan los objetivos de aprendizajes esperados a desarrollar por El Ministerio de Educación de Chile.

En la Figura 04, se presentan los Propósitos declarados por el Ministerio de Educación de Chile (MINEDUC) para la Unidad 1 del Módulo III.

Figura 04: Propósitos MINEDUC Unidad 1, Módulo III. 


\section{Cambio climático como desafío urgente}

¿Qué espero para actuar?

Propósito de la Unidad (MINEDUC)

Esta unidad permite que los estudiantes tomen conciencia de la emergencia climática local y global, propongan vías, considerando interrogantes como:

- ¿Qué es el cambio climático?

- ¿De qué manera me doy cuenta de que el cambio climático está ocurriendo?

- ¿Cuáles son los impactos inmediatos y futuros del cambio climático?

- ¿Cómo explicar la gravedad del cambio climático?

- ¿Cómo puedo proteger y utilizar de manera sostenible los recursos naturales?

- ¿Qué puedo y debo hacer ahora para salvar nuestro planeta?

Gobierno de Chile. Ministerio de Educación (MINEDUC). Bases Curriculares $3^{\circ}$ y $4^{\circ}$ Año Medio.

Fuente: Propia (2020).

II) Sección Recordemos: En la cual se realiza un trabajo de los conocimientos previos a través de reflexiones, autoevaluaciones y diversas actividades que permiten contextualizar al estudiante con la temática a estudiar posteriormente.

A continuación, en las Figuras 05 y 06, se puede observar cómo se lleva a cabo la Sección Recordemos para la Unidad 2 del Módulo III en la temática de Consumo Sostenible.

Figura 05: Acordeón de Conocimiento Previo. Unidad 2, Módulo III.

\section{Recordemos}

Seguramente, hace un par de años tuviste que cambiar el uso de las bolsas plásticas por el uso de bolsas reutilizables..

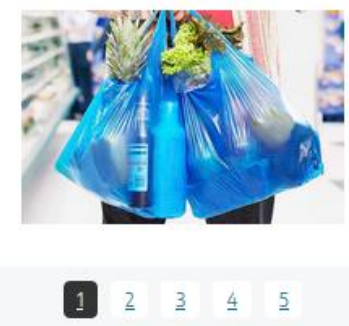

Fuente: Propia (2020). 
Para acceder al vídeo, sólo debes hacer dick en el siguiente enlace: https: / /wwwyoutube.com/watch?v=wCraRKvjoww

¡Disfrutalo!

Fuente: Propia (2020).

III) Contenido Temática, Actividades y Evaluaciones: Una vez realizado el trabajo con conocimientos previos, se realiza la profundización de la temática a desarrollar, presentando el contenido científico para llevar a cabo diversas actividades y evaluaciones las cuales son desarrolladas en función a metodologías y estrategias de enseñanza y aprendizaje tales como: Aprendizaje Colaborativo, Aprendizaje Indagativo, Aprendizaje Basado en Problemas, Aprendizaje Basado en Proyectos, Estrategias Grupo Puzzle de Aronson Etc. Toda el desarrollo del contenido, actividades y evaluaciones son apoyadas en recursos TIC's, tales como videos, imágenes, líneas de tiempo y Softwares de simulación los cuales permiten realizar modelaciones para estudiar diversos fenómenos de estudio, tales como: Cambio climático, efecto invernadero, gases de efecto invernadero, aumento del nivel del mar, etc. Estos Softwares utilizados durante el desarrollo de la Unidad de Aprendizaje, poseen su propio Manual de Usuario elaborado en esta investigación, para así facilitar el uso de estas herramientas de aprendizaje y lograr obtener un máximo beneficio de éstas.

Es fundamental mencionar que cada tópico de las temáticas desarrolladas durante esta Unidad de Aprendizaje, corresponde a tópicos propuestos durante esta investigación, los cuales permitan cumplir con los Objetivos de Aprendizaje por el MINEDUC para llevar a cabo las diversas Unidades de los Módulos III y IV de la asignatura de Ciencias para la Ciudadanía.

A continuación, en las Figuras 07, 08, 09 y 10, se puede observar el desarrollo de contenido, actividades y evaluaciones de diversas temáticas estudiadas en la Unidad 


\section{Didáctica de Aprendizaje desarrollada.}

Figura 07: Desarrollo de Contenido. Unidad 2, Módulo IV (Tecnología y Sociedad).

ENERGÍA NUCLEAR

Historia ¿Qué es la Energía Nuclear? Centrales Nucleares Funcionamiento Centrales Nucleares

\section{Residuos Nucleares}

En la segunda mitad de la década de los sesenta, Estados Unidos lanzó el primer programa nuclear destinado a la generación de electricidad, aunque cuatro años antes, el Reino Unido inauguró Calder Hall, la primera central nuclear del mundo. Poco después, otros países industrializados siguieron el ejemplo llevando a cabo sus propios programas de construcción y explotación de centrales nucleares.

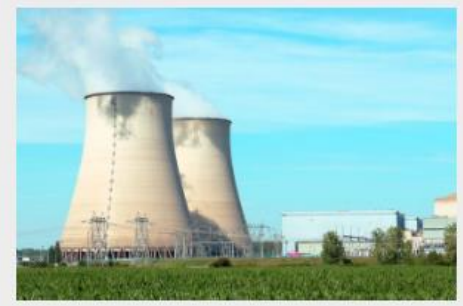

El fuerte crecimiento de la demanda eléctrica y sus prometedoras expectativas económicas fueron el motor del desarrollo de esta fuente energética. A principios de los años setenta la crisis energética del petróleo proporcionó el impulso definitivo a la energía nuclear dentro de los planes energéticos de muchos países industrializados como Alemania, Canadá, Italia y Japón. Destaca la fuerte apuesta por el desarrollo de la energía nuclear que realizó Francia, abandonando los reactores de grafito-gas por la tecnología nuclear. A su vez, otros países como México, Brasil, Taiwán y Corea se prepararon para iniciar sus programas nucleares.

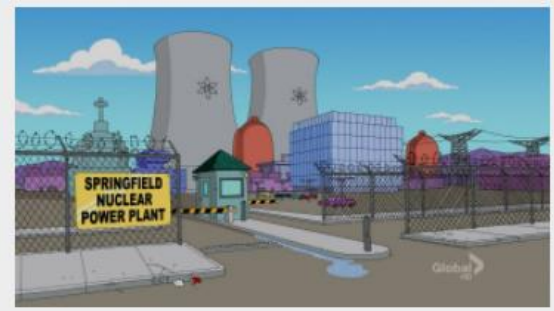

Fuente: Propia (2020). 
IMPLEMENTAÇÃO DE ESTRATÉGIAS PARA O ENSINO DOS MÓDULOS III E IV DAS SUJEITAS CIÊNCIAS PARA A CIDADANIA USANDO TIC

Figura 08: Desarrollo de Actividad. Unidad 1, Módulo III .

MÓDULO III: AMBIENTE Y SOSTENIBILIDAD

ACTIVIDAD PARA DESARROLLAR LA TEMÁTICA DE CAMBIO CLIMÁTICO

ESTA ACTIVIDAD SATISFACE LOS OBJETIVOS

$O A 3-O A C-O A d-O A f-O A i$

DESCRIPCIÓN ACTIVIDAD: La siguiente actividad se desarrollará en forma grupal y se utiliza la metodología de enseñanza de aprendizaje basado en problemas, ABP, lo cual requiere que el curso se divida en grupo. Esta actividad se realizará en 2 sesiones. En la primera sesión, cada grupo elegirá algunos parámetros del Software de Cambio Climático para evidenciar su comportamiento, además de comparar dos parámetros con el fin de observar grados de dependencias entre ellos, además tomará una de las imágenes de análisis presentadas como situación problema, la misión consistirá en trabajar de forma específica para dar respuesta al problema que se está analizando. Finalmente, en la segunda sesión, se realizará la exposición de los grupos de acuerdo a la problemática estudiada en base a los resultados obtenidos durante la primera parte, originando un debate en torno a las posibles soluciones al problema analizado.

CONTEXTUALIZACIÓN DEL PROBLEMA

\section{Cambio Climático}

El cambio climático se ha transformado en una de las mayores amenazas medioambientales que nos han aquejado durante los últimos años.

Factores como la industria, los distintos tipos de energía, el distinto manejo de las energías y la población en general, han llevado a aumentar el impacto de dicho fenómeno en nuestro planeta.

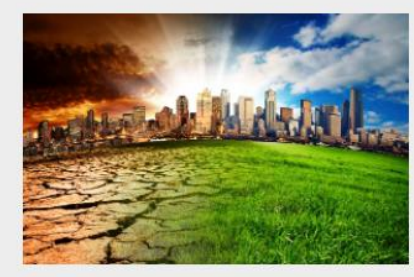

12

SITUACIONES PARA ANÁLISIS

A continuación, se presentan 2 imágenes para ser analizadas. Estas imágenes corresponden a la representación del Planeta Tierra en los años 1978, 2016 y 2030 , mientras que la otra imagen corresponde a un oso polar sufriendo las consecuencias del cambio climático.

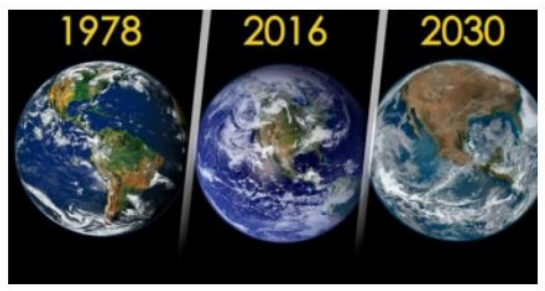

Imaaen de análisis 1

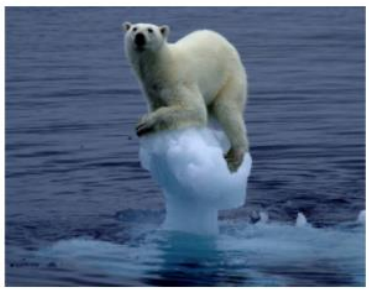

Imanen de análicic ?

Fuente: Propia (2020). 
Figura 09: Software utilizado para llevar a cabo la Actividad de la Unidad 1, Módulo III .

\section{SOFTWARE CAMBIO CLIMÁTICO}

A continuación, se presenta el Software proveniente de Climate Interactive, el cual será utilizado para estudiar Cambio Climático durante esta Unidad.

Este Software, permite llevar a cabo el estudio del cambio climático analizando diversos parámetros tales como:

- Temperatura

- Nivel del mar

- Fuentes de energía

- Entre otros

Esta Sotfware será utilizado en la realización de diversas actividades que se presentarán durante esta Unidad de Aprendizaje.

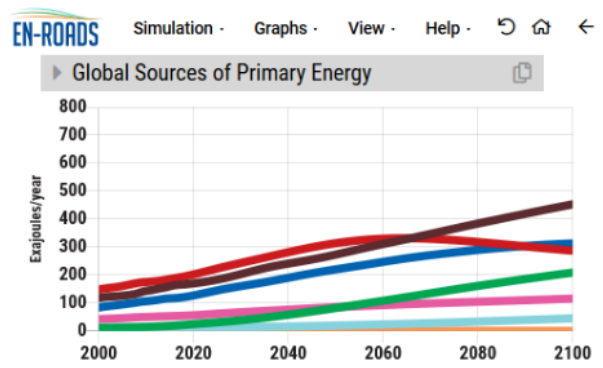

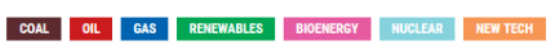

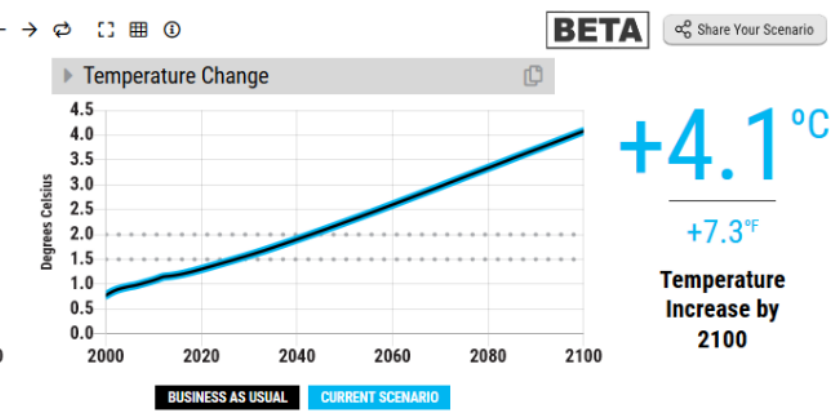

Para acceder al Software realice click en el siguiente enlace:

https://en-roads.climateinteractive.org/scenario.html?v=2.7.15

\section{Recomendaciones}

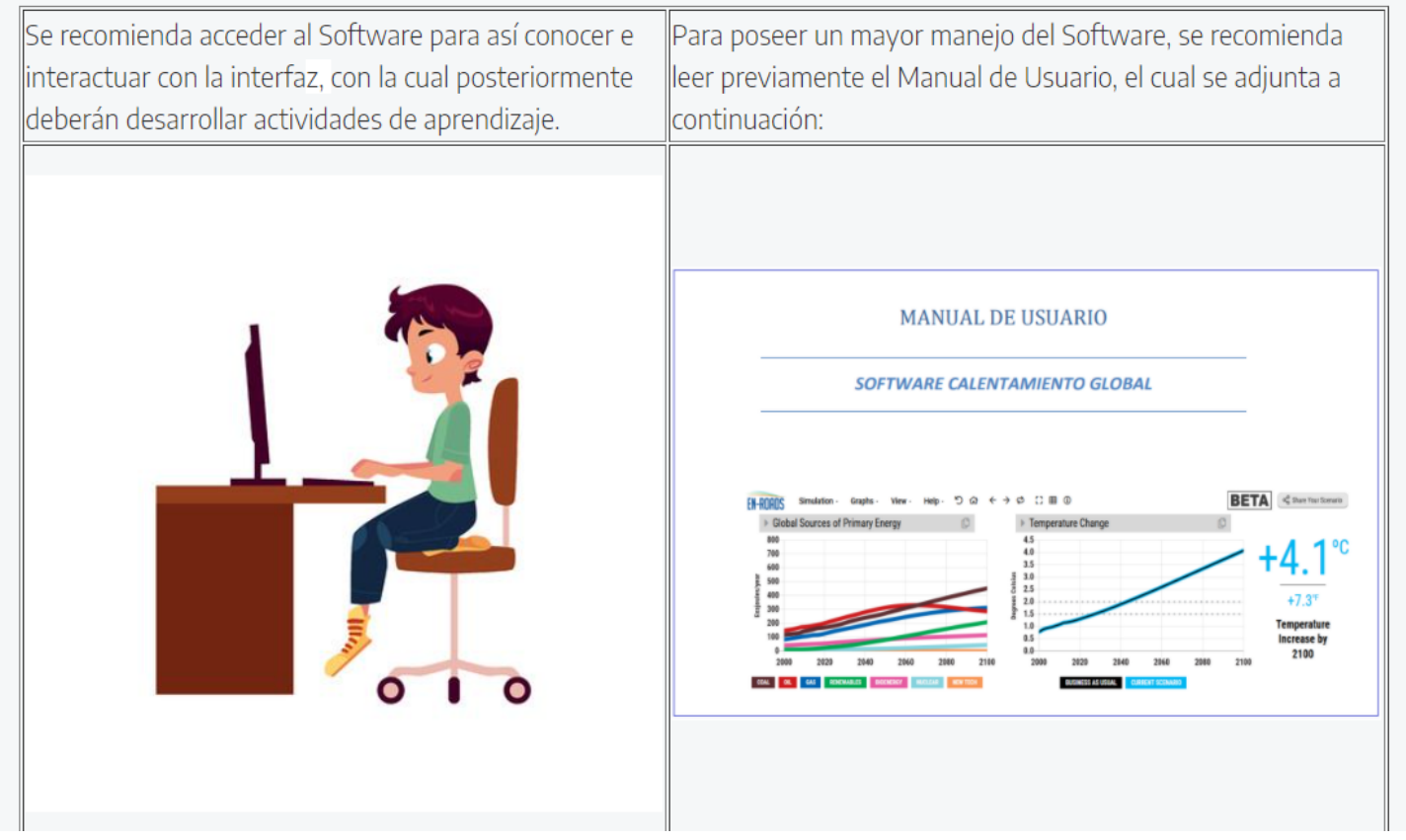

Fuente: Propia (2020). 
IMPLEMENTAÇÃO DE ESTRATÉGIAS PARA O ENSINO DOS MÓDULOS III E IV DAS SUJEITAS CIÊNCIAS PARA A CIDADANIA USANDO TIC

Figura 10: Evaluación, Unidad 1. Módulo IV (Tecnología y Sociedad).

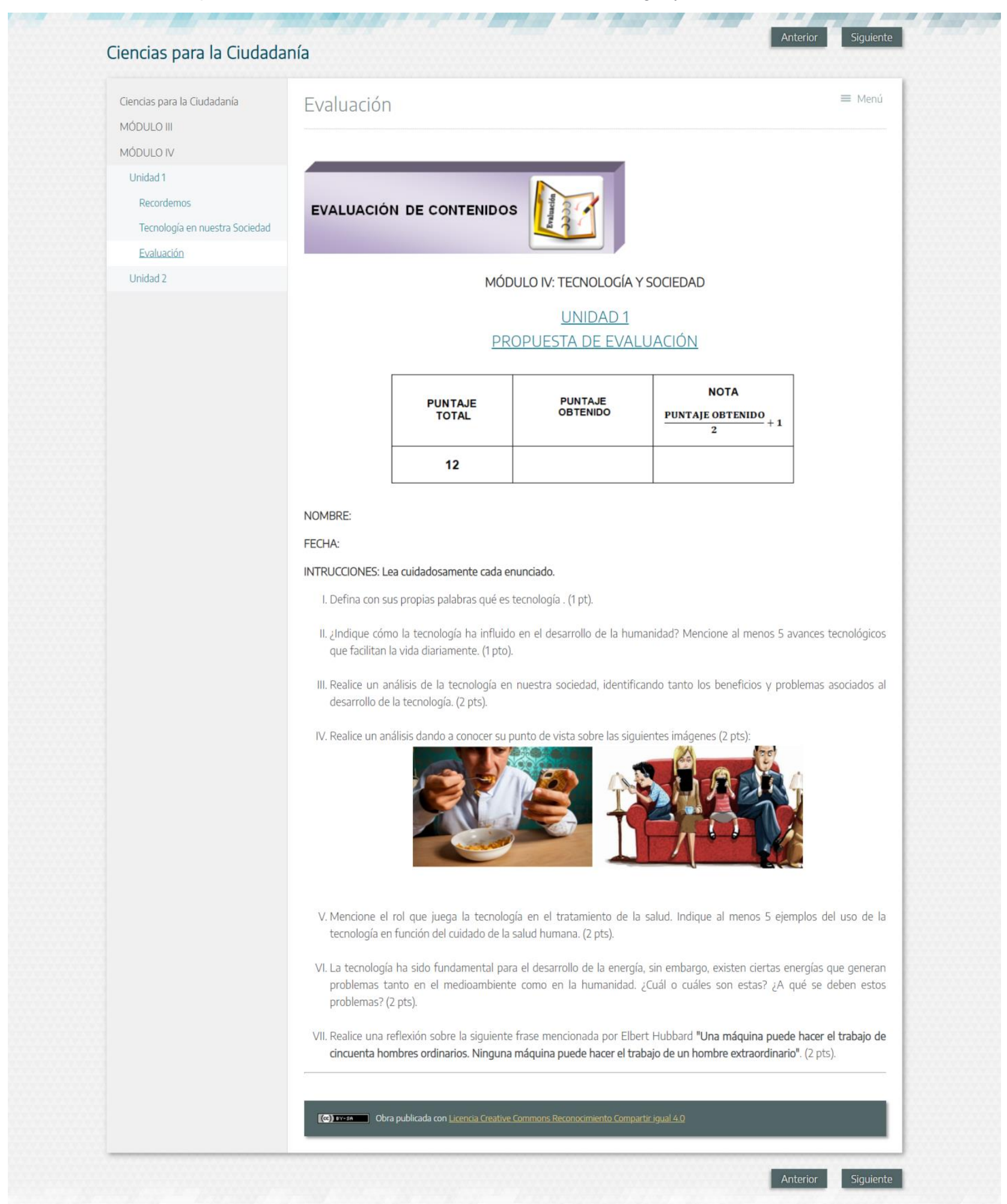

Fuente: Propia (2020).

Link de acceso Unidad Didáctica:

http://www.Soporteeducativo.cl/quimica/cienciaciudadania/mdulo_iv.html 
Validación Unidad Didáctica: A continuación se presentan algunos de los resultados obtenidos durante la validación a través de Juicio de Expertos, llevada a cabo a través de una encuesta (que contiene 4 dimensiones y 14 preguntas ) realizada a 12 profesores del sistema escolar.

Cuadro 01: Validación de Unidad Didáctica.

\begin{tabular}{|c|c|}
\hline $\begin{array}{l}\text { Dimensión Suficiencia: La Unidad Didáctica } \\
\text { contiene los aprendizajes esperados, contenidos y } \\
\text { actitudes involucrados en los módulos } \\
\text { desarrollados. }\end{array}$ & $\begin{array}{l}\text { Dimensión Coherencia: Los temas propuestos } \\
\text { en la Unidad Didáctica son abordados de forma } \\
\text { coherente para cumplir con los objetivos } \\
\text { planteado por el MINEDUC para los módulos } \\
\text { III y IV de CPC. }\end{array}$ \\
\hline $\begin{array}{c}\text { Gráfica 01: Valoración docente - Suficiencia de } \\
\text { contenidos y actitudes }\end{array}$ & $\begin{array}{c}\text { Gráfica 02: Valoración docente - Suficiencia de } \\
\text { contenidos y actitudes }\end{array}$ \\
\hline $\begin{array}{l}\text { Nunca } \\
\text { Raramente } \\
\text { Ocasionalmente } \\
\text { Frecuentemente } \\
\text { Muy } \\
\text { frecuentemente }\end{array}$ & $\begin{array}{l}\text { Nunca } \\
\text { Raramente } \\
\text { Ocasionalmente } \\
\text { Frecuentemente } \\
\text { Muy } \\
\text { frecuentemente }\end{array}$ \\
\hline Fuente: Propia (2020) & Fuente: Propia (2020) \\
\hline $\begin{array}{c}\text { Gráfica 03: Valoración docente - Coherencia } \\
\text { Objetivos. }\end{array}$ & $\begin{array}{l}\text { Dimensión Relevancia: Las imágenes } \\
\text { presentadas son claras, atractivas y despiertan el } \\
\text { interés de los estudiantes. } \\
\text { Gráfica 04: Valoración docente - Recursos de } \\
\text { imagen. }\end{array}$ \\
\hline $\begin{array}{l}\text { Nunca } \\
\text { Raramente } \\
\text { Ocasionalmente } \\
\text { Frecuentemente } \\
\text { Muy } \\
\text { frecuentemente }\end{array}$ & $\begin{array}{l}\text { Nunca } \\
\text { Raramente } \\
\text { Ocasionalmente } \\
\text { Frecuentemente } \\
\text { Muy } \\
\text { frecuentemente }\end{array}$ \\
\hline Fuente: Propia (2020) & Fuente: Propia (2020) \\
\hline
\end{tabular}

Fuente: Propia (2020) 
IMPLEMENTAÇÃO DE ESTRATÉGIAS PARA O ENSINO DOS MÓDULOS III E IV DAS SUJEITAS CIÊNCIAS PARA A CIDADANIA USANDO TIC

Los requerimientos esenciales valorados por los diversos docentes durante esta investigación, logran evidenciar que la unidad didáctica desarrollada cumple con diversos criterios analizados, tales como criterios de la dimensión de suficiencia, donde puede concluir que los contenidos, actitudes y aprendizajes esperados por cada Módulo desarrollado dentro de la Unidad Didáctica de aprendizaje logra cumplir con este aspecto de forma muy frecuentemente.

Por otro lado, de la dimensión de Claridad, se puede concluir que la Unidad Didáctica posee una navegación ergonómica, la cual permite una experiencia de lectura fácil y fluida, respetando las normas de redacción y ortografía.

De la dimensión de Coherencia, se puede concluir a través del análisis del parámetro "coherencia de los temas propuestos con los objetivos planteados por el MINEDUC" que la Unidad de aprendizaje permite cumplir de forma eficaz con lo propuesto en las Bases Curriculares del MINEDUC para los Módulos III y IV de la asignatura de Ciencias para la Ciudadanía, siendo esta una herramienta pertinente y adecuada para llevar a cabo el proceso educativo acorde a lo establecido por el ministerio de educación.

Finalmente, de la dimensión Relevancia, se puede concluir que los recursos utilizados en la Unidad Didáctica de Aprendizaje desarrollada en la Plataforma Web de Exelearning, permiten estimular motivación e incentivar a los estudiantes para realizar el proceso de enseñanza y aprendizaje.

\section{CONCLUSIONES}

La presente investigación "Implementación de estrategias para la enseñanza de los Módulo III y IV de la asignatura Ciencias para la Ciudadanía utilizando las TIC's" busca generar nuevas estrategias de enseñanza y aprendizaje para la impartición de la asignatura antes mencionada, poniendo énfasis en el uso de las TIC's como herramienta que permite construir materiales que favorezcan el aprendizaje de los estudiantes secundarios, estos insumos fueron recabados en el diagnóstico realizado a docentes del sistema educativo, dicho diagnóstico marcó el inicio del presente trabajo, donde se detectaron diversas problemáticas en la impartición de los módulos señalados.

A través de la Plataforma Web Exelearning se construyó la Unidad Didáctica de Aprendizaje, con la cual se pretende responder a las diversas problemáticas de aspecto curricular detectadas inicialmente en el diagnóstico, tales como:

- $\quad$ Problemas de contenido: profundidad y dominio.

- $\quad$ Problemas de carencia en las estrategias de enseñanza.

- $\quad$ Problemas de carencia en diversas formas de evaluación de contenido. 
Es posible concluir que la Unidad Didáctica desarrollada para la asignatura de Ciencias para la Ciudadanía, es un recurso que permite implementar diversas metodologías y estrategias de enseñanza para realizar evaluaciones y actividades de aprendizaje apoyadas en el uso de diversos recursos didácticos informatizados tales como Software, vídeos, imágenes, etc.

Además dicha unidad logra cumplir de forma eficiente con los requerimientos esenciales para desarrollar diversos procesos de aprendizajes durante los Módulos III y IV de dicha asignatura.

Por ende, es posible detectar a la luz de los resultados, que la Plataforma Web Exelearning, es una herramienta TIC, que permite elaborar una unidad didáctica adecuada, sencilla, que posibilita el logro de los objetivos planteados para los Módulos III y IV de la asignatura de Ciencias para la Ciudadanía, a través del desarrollo de diversas metodologías y estrategias de enseñanzas, permitiendo dar respuesta a las problemáticas de los docentes detectadas inicialmente en esta investigación.

\section{REFERENCIAS}

\section{LIBROS}

ELLIOTT,J. (1993): El cambio educativo desde la investigación acción. Madrid. Morata.

FIGUEROA, J. G (1976) Estudos de Redes Semánticas Naturais e alguns procesos básicos. UNAM

GÓMEZ J. P., ONTORIA-PEÑA A., MOLINA-RUBIO, A.(1999). Potenciar la capacidad de aprender y pensar. Madrid. Nárcea.

KEMMIS, S. y McTAGGART, R. (1988): Cómo planificar la investigación-acción. Barcelona. Laertes.

LATORRE, A. (2003). La investigación-acción: conocer y cambiar la práctica educativa. Barcelona. Editorial Graó, de IRIF, S.L.

LOMAX, P. (1990): Managing Staff development in Schools. Clevedon: MultilingualMatters.

MINEDUC (2020). Bases Curriculares $3^{\circ}$ y $4^{\circ}$ Medio. Ministerio de Educación. Gobierno de Chile:

Primera

Edición.

MINEDUC (2013). SIMCE TIC. Gobierno de Chile: Enlaces del Ministerio de Educación.

PIMIENTA J. (2012) Las competencias en la docencia universitaria. México pp 2-32 Editorial Pearson Primera edición. 
IMPLEMENTAÇÃO DE ESTRATÉGIAS PARA O ENSINO DOS MÓDULOS III E IV DAS SUJEITAS CIÊNCIAS PARA A CIDADANIA USANDO TIC

POPE, J. (2012), Investigación de mercados. Guía maestra para el profesional, Norma, Bogotá.

ZAPATA (2006). La aventura del pensamiento crítico. Herramientas para elaborar tesis e investigaciones socioeducativas. Editorial Pax: México.

\section{PUBLICACIONES PERIÓDICAS}

ARTEAGA-PAZ Y BASURTO-VERA. (2017) Una aproximación teórico conceptual a la tecnología educativa. Dominio de las ciencias, Vol (3) 657-675.

AUSín, V., ABEllA, V., DElGADO, V., Y HORTIGÜELA, D. (2016). Aprendizaje Basado en Proyectos a través de las TIC: Una Experiencia de Innovación Docente desde las Aulas Universitarias. Formación Universitaria, 9(3), 31-38.

BRAVO, A., RAMÍREZ, P., FAÚNDEZ, A., Y ASTUDILLO, F. (2016). Propuesta Didáctica Constructivista para la Adquisición de Aprendizajes Significativos de Conceptos en Física de Fluidos. Formación Universitaria, 9(2), 105-114.

CABERO ALMENARA, JULIO Y LLÓRENTE CEJUDO, MARÍA DEL CARMEN. (2013). La aplicación del juicio de experto como técnica de evaluación de las tecnologías de la información (TIC). Eduweb. Revista de Tecnología de Información y Comunicación en Educación, vol. $\quad 7, \quad$ núm. $2, \quad$ pp.11-22.

ESCOBAR PÉREZ, JAZMINE Y CUERVO MARTÍNEZ, ÁNGELA. (2008). Validez de contenido y juicio de expertos: una aproximación a su utilización. Avances en Medición, vol. 6, núm. 1, pp. 27-36.

FAÚNDEZ, CLAUDIO A, BRAVO, ALICIA A, MELO, ALEJANDRA D, \& ASTUDILLO, HERNÁN F. (2014). Laboratorio Virtual para la Unidad Tierra y Universo como Parte de la Formación Universitaria de Docentes de Ciencias. Formación universitaria, 7(3), 33-40.

FAÚNDEZ, CLAUDIO A, BRAVO, ALICIA A, RAMÍREZ, GLENDA P, \& ASTUDILLO, HERNÁN F. (2017). Tecnologías de la Información y la Comunicación (TIC) en el Proceso de Enseñanza-Aprendizaje de Conceptos de Termodinámica como Herramienta para Futuros $\begin{array}{llll}\text { Docentes. } & \text { Formación } & \text { 40(4), } & \text { 43-54 }\end{array}$

IVÁN, R., SÁNCHEZ, S., Y RAMIS, F.J. (2004). Aprendizaje significativo basado en problemas. Horizontes $\quad$ Educacionales, $101-111$.

MERAYO (2019). Qué es exelearning y para qué sirve. Máxima Información. Recuperado de: $\quad$ https://www.maximaformacion.es/e-learn/que-es-exelearning-y-para-que-sirve/

MILAGROS (2017). Módulo didáctico Matetic, en exelearning, en el desarrollo de la capacidad resolución de problemas con ecuaciones en z, en los estudiantes de primer grado de la institución educativa "Amalia Campos de Beleván” del distrito de pítipo, 2015. Escuela de Postgrado, Universidad César $\quad$ Vallejo.

ORTEGA-VERGARA, J. D., Y MEDINA-PAYAREZ, I. J. (2015). Modelo Blended Learning para el desarrollo de competencias lectoras y escritoras: un desafío de aprendizaje en 
educación básica primaria en la Institución Educativa San Roque, Colombia. Memorias, 13(23), 93-106.

ROBLES GARROTE, PILAR Y ROJAS, MANUELA DEL CARMEN. (2015). La validación por juicio de expertos: dos investigaciones cualitativas en lingüística aplicada. Revista Nebrija de Lingüística Aplicada, núm. 18. 